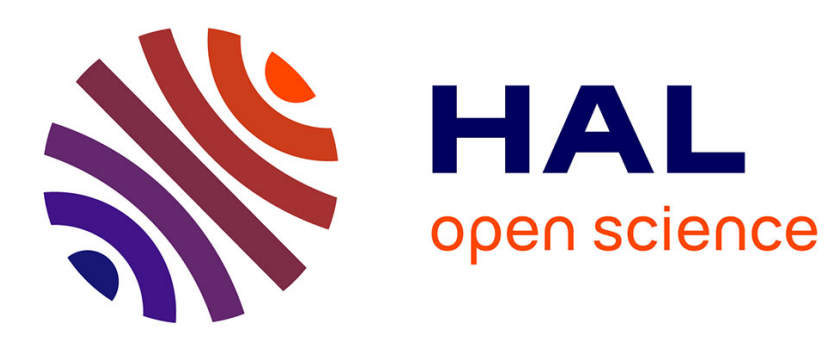

\title{
Communication During Bushfires, Towards a Serious Game for a Serious Matter
}

\author{
Carole Adam, Charles Bailly, Julie Dugdale
}

\section{To cite this version:}

Carole Adam, Charles Bailly, Julie Dugdale. Communication During Bushfires, Towards a Serious Game for a Serious Matter. International Journal of Information Systems for Crisis Response and Management, 2018, 10 (2), pp.79-105. 10.4018/IJISCRAM.2018040104 . halshs-02107035

\section{HAL Id: halshs-02107035 https://shs.hal.science/halshs-02107035}

Submitted on 23 Apr 2019

HAL is a multi-disciplinary open access archive for the deposit and dissemination of scientific research documents, whether they are published or not. The documents may come from teaching and research institutions in France or abroad, or from public or private research centers.
L'archive ouverte pluridisciplinaire HAL, est destinée au dépôt et à la diffusion de documents scientifiques de niveau recherche, publiés ou non, émanant des établissements d'enseignement et de recherche français ou étrangers, des laboratoires publics ou privés. 


\title{
Communication During Bushfires, Towards a Serious Game for a Serious Matter: Communication During Bushfires
}

\author{
Carole Adam, Univ Grenoble-Alpes, LIG, Grenoble, France \\ Charles Bailly, Univ Grenoble-Alpes, LIG, Grenoble, France \\ Julie Dugdale, Univ Grenoble-Alps, LIG, Greenoble, France
}

\begin{abstract}
Australia is frequently hit by bushfires. In 2009, the 'Black Saturday" fires killed 173 people and burnt hectares of bush. As a result, a research commission was created to investigate, and concluded that several aspects could be improved, in particular better understanding of the population actual behaviour, and better communication with them. The authors argue that agent-based modelling and simulation is a great approach to provide tools to improve mutual understanding: let managers test communication strategies, and let residents understand the managers' perspective. Concretely, they extended an existing simulator with a theoretically-grounded communication model based in social sciences; they added user interactivity with the model and investigated gamification to turn it into a serious game to involve the general public. The authors present the results of first experiments with different communication strategies, providing valuable insight for better communication with the population during such events. Finally, they discuss future extensions and generalisation of this simulator.
\end{abstract}

\section{KEYWORDS}

Agent-Based Modelling and Simulation, Communication, Crisis Management, GAMA Platform, Gamification, Serious Game

\section{INTRODUCTION}

Nowadays, the number of crisis events is continuously increasing, be they natural disasters (fires, floods, earthquakes, tsunamis, etc.) or man-made events (industrial accidents, terrorism, refugees flow, etc.) (Guha-Sapir et al., n.d.).

In this paper, we are interested in the bushfires that strike the state of Victoria in Australia every summer, burning many hectares of forest, causing numerous deaths and injuries, and destroying property. There has been a $40 \%$ increase in the number of bushfires per week in Australia over 5 years (from 3284 per week in 2007 to 4595 events per week in 2013) (Dutta, Das, \& Aryal, 2016). The current state policy is "Prepare, stay and defend, or leave early." Thus, the population is given a choice between: evacuating early, before fire reaches their area of residence because "many people have died trying to leave at the last minute" (Country Fire Authority, 2014); or stay and defend their house, which is feasible only if a person is very well prepared both physically and mentally. In both cases, the decision must be made and a plan prepared well in advance. However, in the summer of 2009 , serious bushfires devastated a part of Victoria, culminating on the Black Saturday $7^{\text {th }}$ February 
when 173 people died despite all efforts at raising awareness. The cost of these bushfires was estimated to be 4.4 billion Australian dollars, 98932 hectares of Victorian parks were damaged, and around one million animals died with a devastating impact on agriculture due to loss of cattle and pastures, etc.

Several reports have tried to explain the reasons for this heavy death toll (Teague, McLeod, \& Pascoe, 2009a; McLennan \& Elliott, 2011). These reports identified three main inconsistencies: first, in behaviour in that the population did not react as expected by the decision-makers; secondly in information content since the population did not always considered the information they received to be relevant to them; and lastly in communication means, which was felt to be inefficient, especially in the case of information broadcast.

Societies can manage such crisis and emergency situations in several ways: adopt urban and territory planning policies to reduce the risks (e.g. forbid construction in exposed areas); raise awareness and prepare the population in advance; or create efficient emergency management policies to deal with crises when they happen. In this perspective, computer modelling and simulation is a powerful tool to test the effects and complex interactions of these different strategies without waiting for an actual crisis to happen. Human lives need not be put at risk and the cost of experimenting with different strategies is greatly reduced. Furthermore, it offers a great degree of control on all conditions and the possibility of reproducing exactly the same situation as many times as needed at no cost. When modelling human behaviour, mathematical, equation-based models are too limited (Parunak, Savit, \& Riolo, 1998). On the contrary, agent-based models, where autonomous entities (agents) interacting with each other represent the humans involved, offer many benefits (Bonabeau, 2002). They allow capturing emergent phenomena that characterise such complex systems; they provide an intuitive and realistic description of their behaviour; they are flexible, offering different levels of abstraction by varying the complexity of agents.

As a result, many previous works have used agent-based modelling and simulation to study human behaviour in natural disasters and provide tools for emergency managers. In particular, Adam et al. (Adam \& Gaudou, 2016) have designed a model of the behaviour of the Australian population in bushfires from interviews gathered after the 2009 "Black Saturday" fires by the Victorian Bushfires Research Commission (Teague, McLeod, \& Pascoe, 2009b). This model aims to explain the inconsistencies observed in behaviour, in terms of a gap between objective and subjective evaluations of both risk and individual capabilities to deal with it. Their evaluation proves that the model provides good explanation for the inconsistencies in behaviour noted in the report. However, the agents in their model only represent the population, and they do not communicate with each other; as a result, this model is unable to tackle the communication problems also noted in the report.

Our hypothesis is that these communication issues are a side effect of this same misunderstanding between residents and authorities, where the content and type of messages sent are chosen based on erroneous assumptions about the population's expectations. This is consistent with Rhodes' conclusion, stating that "agencies need to change from an expert authoritative approach to one that seeks to understand community needs and expectations" (Rhodes, 2014). It is also in agreement with (Steelman et al., 2015) who claim that the point of view of the population receiving the messages is often neglected; they surveyed 873 people concerned with five wildfires occurred in the USA in 2009 and 2010, asking questions about what information they found useful, trustworthy, and which information they actually used, during these fires; they found out that the sources used were not necessarily the sources rated as most useful or trustworthy.

Therefore, we believe that improving mutual understanding can improve communication during similar crises in the future. Concretely, each side need better understand the other side's point of view. Our research question is now: how can we get practitioners to understand how the population deals with their messages and what sort of messages they expect? And how do we get the population to better understand what messages the practitioners can or cannot send, and how they are expected to behave in response? 
Our approach is to use an agent-based model as the basis for an interactive simulator where the user can play the role of the practitioners in charge of communicating with the population during fires. If used by real practitioners, it will be a decision-support tool that lets them experiment with possible communication strategies, get insight on their potential impact on and usefulness for the population, and understand if they work and why (or why not). If used by members of the population, it will be a serious game that raises awareness by providing them with insight on the challenges faced by practitioners when trying to communicate with them during a fire.

Concretely, we want to turn Adam \& Gaudou's model into an interactive simulation where the user can test different communication strategies (changing the source, media, content or recipient of messages) and obtain indicators of their relative success on different profiles of residents. For such an interactive simulation to lay valid results, it is important that the underlying human behaviour model be as realistic as possible (van Ruijven, 2011). The underlying agent-based model was proven valid (Adam \& Gaudou, 2016) and successfully compared with another more complex model (Adam, Taillandier, \& Dugdale, 2017). Here we enrich it with a communication model in order to allow the agents to receive messages and to reason on their content and sender. To ensure the validity of these additions, our communication model is grounded in theories from social sciences that have studied communication issues for a long time. Its output is also compared with the population interviews performed after the 2009 bushfires.

The paper is structured as follows: we first quickly describe the existing simulator that serves as the basis for our own. The next section introduces our communication-oriented model of population behaviour, the different theories that it is grounded on: communication theory, behaviour change theory, and cognitive biases theory, and how we implemented these. The following section exposes experiments with this interactive simulator used as a decision-support tool for stakeholders, and results in terms of comparison of various communication strategies. The penultimate section discusses gamification literature, another successful example in crisis management, and a specification of gaming design elements that will be added to this model to turn it into a serious game for the population. Finally, we conclude the article by discussing the limitations of our approach and its future prospects.

\section{EXISTING SIMULATOR}

Our simulator is an extension of an existing model, designed from an analysis of the interviews, implemented in GAMA, and validated against behaviour statistics (Adam \& Gaudou, 2016). In this section we give a quick overview of this simulator.

\subsection{GAMA Platform}

GAMA (Grignard. et al., 2013; Drogoul, Grignard, et al., 2013; Drogoul, Amouroux, et al., 2013) is an open-source platform for agent-based modelling and simulation, offering an integrated programming language and development framework to develop elaborated models with up to several millions of agents. The GAma Modelling Language (GAML) is a high-level agent-based language based on Java, specifically designed to be easy to use even for non-computer scientists, allowing domain experts to create and maintain their own models. GAMA also provides native management of GIS (Geographical Information Systems) data allowing integrating geographical data files into simulations. Finally, GAMA offers interactive functions (user commands) enabling the use of the participatory dynamics required in our interactive simulation.

\subsection{Existing Simulator}

Adam and Gaudou (Adam \& Gaudou, 2016) have implemented in GAMA an agent-based simulator of the behaviour of the Australian population in bushfires, based on the population interviews gathered after the 2009 fires (Teague et al., 2009b). In their simulator, the world is a grid of 50*50 cells inhabited by four species of agents: fires, houses, shelters and residents (see a screenshot in Figure 1). 
Fires are reactive agents; they are initially placed randomly on a free cell and then grow up randomly at each cycle, increasing their intensity (which directly increases the damage they deal) and size. People cannot go through fires when escaping but can cross their area of effect (representing the smoke and heat zones around the fire). When all fires are extinguished, the simulation stops automatically.

Houses are inhabited by exactly one resident (no families). They offer some amount of protection but residents can still be hurt if fires are close enough. Houses can be reinforced by their owner up to a given point while fires are still far away. When fires are close enough, they deal damage to the house until possibly destroying it.

Shelters are safe areas where people cannot be harmed by fires. Residents know the location of some shelters, and when choosing to escape they aim at the closest one they know (which might not be the absolute closest one if they ignore its location).

\subsection{Residents Model}

Finally, residents are the most complex agents in this simulator. They have various attributes to represent their health, their motivations (to defend or to escape), their risk perception (awareness of fire, assessment of danger), and their abilities. Their possible actions are to prepare their house and themselves, to escape towards a shelter, to defend against the fire, or to take cover in their house. The choice of action is determined by a finite state machine architecture (see Figure 2): in each state, the corresponding action is performed, and the transitions to another state are constrained by the values of attributes and the position of fires.

The initial state is Unaware; residents who perceive or are informed of fires then switch to the next state Indecisive, until they make a decision. The FSM then has 3 branches: residents who prefer

Figure 1. GAMA simulation screenshot. The 3 big green circles are the shelters. Red triangles are the fires, surrounded by a yellow impact zone. The smaller circles are the residents, with their colour showing current state (blue: unconcerned; orange: preparing; red: defending; pink: evacuating).

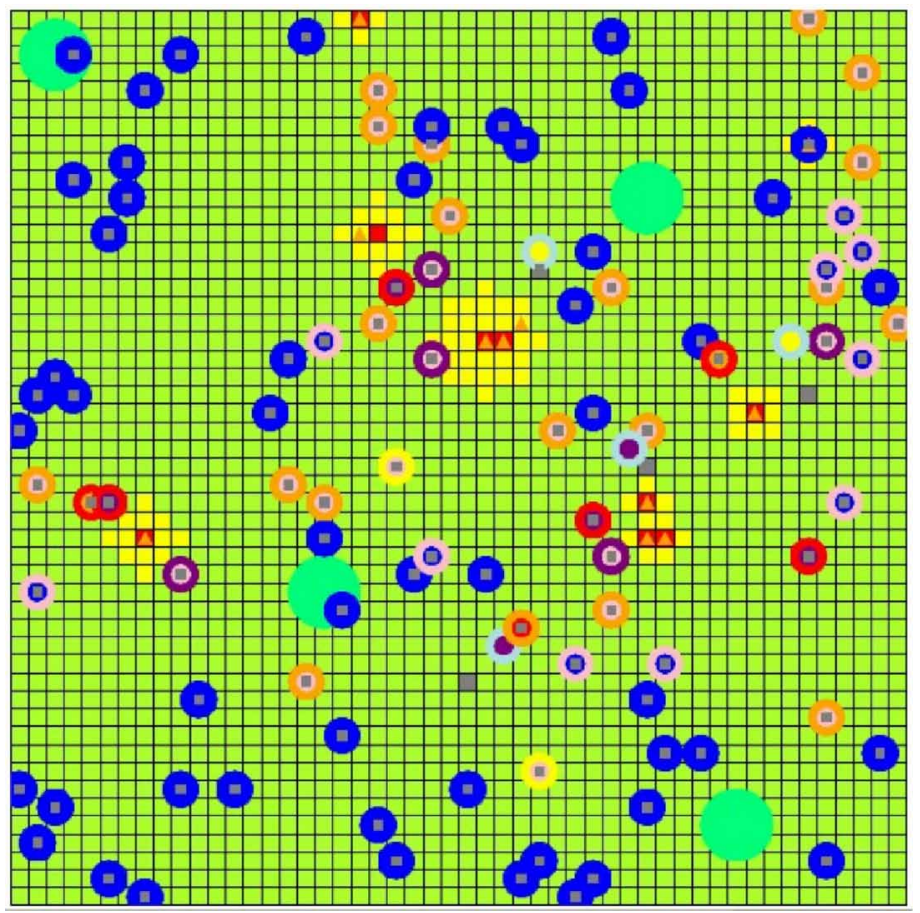




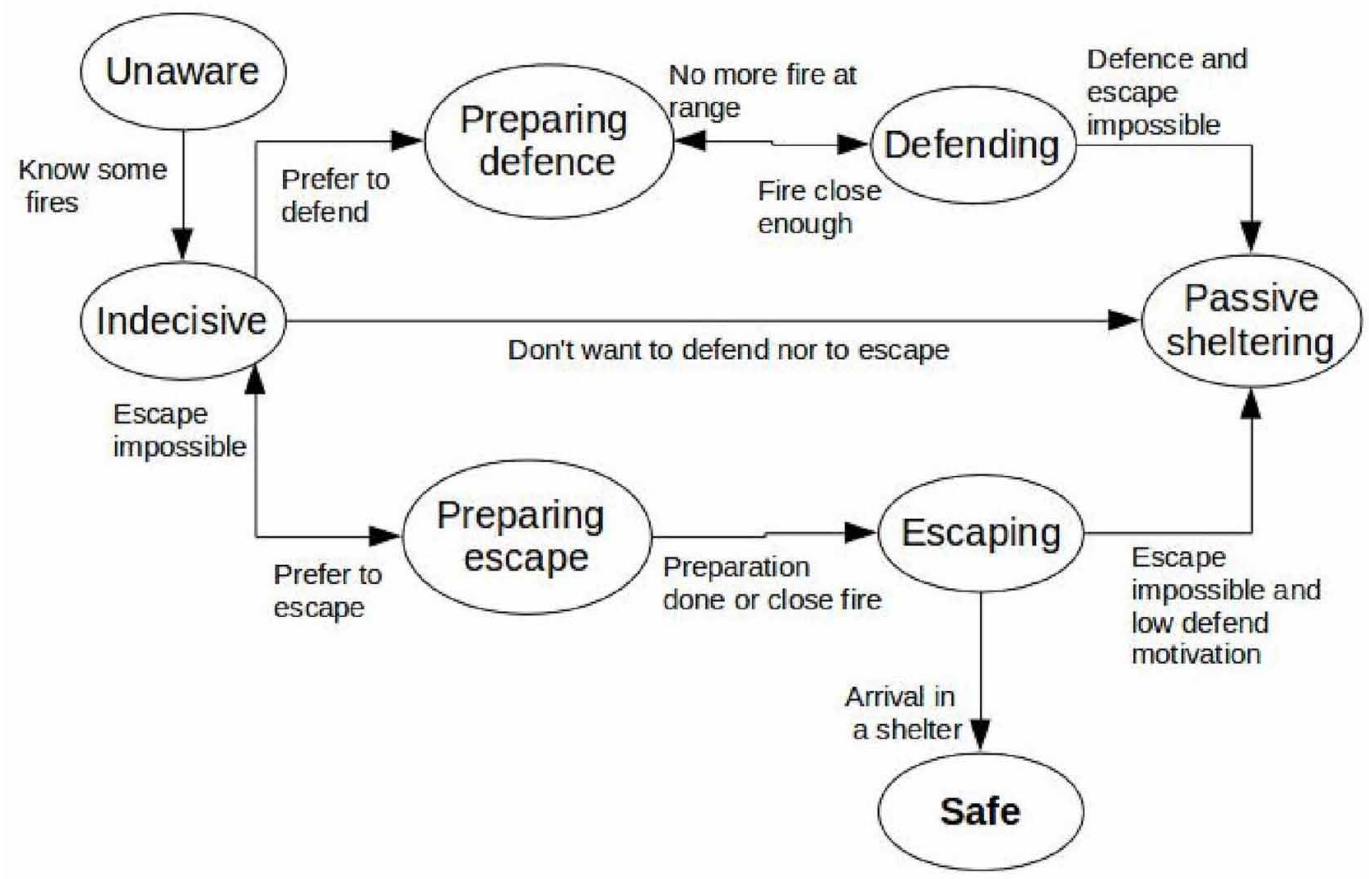

to defend their house move on to Preparing defense until ready or forced to move to Defending; residents who prefer to flee move to Preparing escape until ready or forced to switch to Escaping by proximity of the fire; finally, the other residents, motivated neither to escape nor to defend, enter the Passive sheltering state. This state can also be entered from Defending or Escaping when the situation makes it impossible to pursue in these states. Pedestrians also have two other final states, which can be reached from any other non final one. The first state is Dead, and occurs when people took more damages from fires than their resistance. The second is Survivor, if they are still alive and out of a safe area at the end of the simulation.

\subsection{Limitations}

This model was proven valid to describe the population (physical) behaviour, that is their decisions to stay and defend, or evacuate towards safe areas. However, it does not cover communication at all. A later version has covered communication inside the population (Adam \& Dugdale, 2018), but communication between the authorities and the population was not covered, which is essential if it is to be improved. Therefore, we intend to enrich this model with new features to cover this aspect, as described below.

\section{COMMUNICATION-ORIENTED MODEL}

The following paragraphs describe why and how we improved this model with communication features.

\subsection{Importance of Communication in Crisis}

Communication is essential during disasters but also very challenging (Manoj \& Baker, 2007) due to the information overload and time pressure on deciders. (Palttala et al., 2012) provide an overview of communication constraints during disasters, and performance indicators for measuring 
the quality of disaster communication strategies. (Ran, 2011) focuses on the importance of resilient communication infrastructure to avoid their destruction during an earthquake; they do not study the content of communication.

(Steelman \& McCaffrey, 2013) study how the theoretical best practices in risk and crisis communication can apply in practice to communication before and during wildfires in 3 states of the U.S.A. Our approach is slightly different in that we aim to provide a tool to let stakeholders explore communication strategies, understand their impact on the (simulated) population, and improve their communication as a result. We believe that mutual understanding is more important than blindly following theoretical best practices. This section explains how we use sociological and psychological theories about communication to design a model of how the population reacts to messages, to be used in our simulator.

\subsection{Communication Strategies}

\subsubsection{Communication Theories for Crisis Management}

In his well-known Communication Theory, Shannon (Shannon, 1948) devised a model of communication with the following components: information source, transmitter (encoder), transmission channel, receiver (decoder), destination, and message.

Here we are concerned with official messages, whose source are the fire authorities in charge of dealing with the crisis, and whose destination (or target) is the population, either as a whole, in subgroups, or individual people. The channel to send these messages can vary, from door-to-door visits, to radio or television, or social media. The choice of a channel has already been largely studied in crisis management. For instance some works show a significant "channel effect" of social media (Schultz, Utz, \& Göritz," 2011; Utz, Schultz, \& Glocka, 2013), where the same message has a different effect depending on which channel it is delivered on (social media vs more traditional channels).

Regarding the message itself, Speech Acts Theory (Searle, 1969; Vanderveken, 1990) exhaustively lists the 5 types of messages that can be communicated: assertive (state a fact, provide an information), promissive (commit to perform an action), directive (ask or order the hearer to perform an action), expressive (express an emotion), and declarative (formal institutional action such as declaring someone married, or guilty). Most relevant in crisis management are assertive and directive speech acts. Indeed, our analysis of the interviews has shown that most messages received by the population were either recommendation about what to do (directive speech acts) or information about the progression of the fire (assertive speech acts). In our model we have therefore limited the available messages to these two types, but more messages can be added in the future.

\subsubsection{Implementation of Communication Strategies}

Based on the communication theories presented above, we implemented several types of communication strategies, which concern the different components of a message, namely the choice of its source (authorities, fire soldiers, general media...), its content (information, recommendations), and its target (all the population, a precise geographic area, or a specific category of residents):

- Content-based strategies: Focused on what is concretely told to residents. We modeled two of the 5 types of speech acts: information about fires (e.g. position) and recommendations (advice about the appropriate behaviour, e.g. evacuate). Indeed, these are the ones most frequently reported by the residents in the interviews, either because they received them, or because they wish they had received them. More contents can be added in future work;

- Target-based strategies: Concern the accuracy of messages. We modeled three possibilities: global broadcast (target all residents), geographical-based (target people in a specific area), and plan-based (target residents based on their declared fire plan: defend or escape). Broadcast is the 
strategy reported in the interviews, while more targeted communication is what the interviewees wish had happened;

- Source-based strategies: Concern the emitter of the message. We have implemented different possible sources (firemen, authorities...) as well as indirect communication strategies where global authorities send messages to local managers (e.g. mayors) who filter them and spread relevant data to their neighbourhood;

- Composed strategies: Consist in sending a sequence of messages in a precise order. This type of strategies aims at determining if it is efficient to send a combination of several messages, and which order of messages is most efficient (for instance inform about fires before or after giving recommendations);

- Shelter-based strategies: In order to compare the efficiency of building many shelters vs communicating more about the existing ones. These are therefore not strictly communicative strategies as the player can also choose to create new shelters. Shelters are designated safe areas (cricket oval, community house, etc.) where residents are invited to gather in case of a fire.

We implemented these communication strategies in the existing GAMA simulator in the form of user actions: the user can right click in the simulation window at any time during the simulation; they are then invited to select a communication strategy and specify its features (source, channel, etc.) before executing it. Each communication action has a different cost (for instance it is more costly to accurately target communication than to broadcast, and more costly to build shelters than to advertise them). In the next paragraph, we describe how we also updated the residents model to allow these agents to receive messages, interpret them, reason on them and make relevant decisions so as to change (or not) their subsequent behaviour.

\subsection{Behaviour Change}

The goal of the communication strategies described above is ultimately to get the population to change their behaviour during a disaster, towards what the emergency managers consider to be the best response (evacuate to a safe area after an earthquake, stay confined inside during a chemical incident, etc.). But the practitioners admittedly do not understand why the population does (or does not) adapt their behaviour accordingly (Rhodes, 2014). In order to help them gain understanding in that matter, we grounded our model of the population reaction to messages on psychological literature about behaviour change, as detailed below.

\subsubsection{Listening Process and Possible Failures}

(DeVito, 2000) has divided the listening process into 5 sequential phases that occur after actually hearing the message: receiving (or attending, i.e. actually focusing on the message), understanding (getting the meaning of the message), remembering, evaluating (forming an opinion about the validity of the message), and responding (i.e. provide feedback regarding acceptance of the message). This final stage can be in the form of direct feedback, or just by changing behaviour as a result of the message.

Communication can fail at any stage of this process. The message might not be heard if the recipient is not monitoring the channel (TV or radio is off). Even if the message is heard, it might not be attended to or remembered if the hearer is overwhelmed by receiving too much information at the same time (information overload); the hearer might miss relevant data that is drowned in too many irrelevant messages, which might lead them to stop listening to a given emitter because they cannot deal (Austin, Pinkleton, \& Fujioka, 1999). If attended to, the message might be evaluated as irrelevant or inaccurate and discarded. Finally, even if the message is considered accurate, it might not lead to the expected behaviour change.

In particular, trust in the source of the message is important to evaluate its accuracy and whether to act upon it. Three main factors of trust have been discussed in the Elaboration Likelihood Model: expertise, trustworthiness, and attractiveness (Petty \& Cacioppo, 1986). 


\subsubsection{Psychology of Behaviour Change}

Behaviour change has been extensively studied (see (Prager, 2012) for a review), but a lot of works focus on medium or long-term changes (e.g. non-healthy habits like smoking) while bushfires are short-term emergency situations.

The Elaboration Likelihood Model (Petty \& Cacioppo, 1986) is a theory describing how attitudes can be changed by persuasive stimuli. It distinguishes two types of processing: central (cognitive, high effort) and peripheral (heuristic, low effort):

- The central route of processing, used when the individual is motivated and able to process the message carefully, is a more cognitive, high-effort elaboration of messages received, based on actual logical value. As a result, it leads to more resistant attitude change, and is more predictive of behaviour change;

- The peripheral route of processing, used to reduce mental efforts when the individual is not motivated or unable to process the message, is a less thorough elaboration of messages that relies more on cues and heuristics. For instance, it focuses on the credibility, attractiveness or familiarity of the source, at the expense of the actual logical content value. It is therefore more influenced by mood, or by emotions towards the emitter.

According to this model, individuals try to reduce their mental efforts and will thus tend to use the peripheral route, unless they are sufficiently motivated and able to elaborate on the message:

- Motivation: Affected by the relevance, interest and consistency of the message with the recipient's current beliefs (contradictory messages are more easily rejected); it is also affected by the recipient's personality (do they like thinking, whatever the subject);

- Ability: Affected by the recipient's knowledge (is it sufficient to critically evaluate the content of the message) and familiarity with the subject, and the availability of their cognitive resources (how busy or distracted they are, time pressure).

As we can see, peripheral processing is more likely to happen during disasters due to the stress and time pressure. However, it leads to less lasting attitude changes and is less likely to trigger behaviour change. This is also in agreement with (Kahneman \& Egan, 2011). Crisis communication should therefore be adapted so as to favour central processing, by sending only clear and relevant information that the receivers are more likely to understand and accept.

\subsubsection{Implementing Residents Behaviour Change}

In order to obtain a realistic model of residents and of their handling of messages, we implemented several psychological phenomena based on the theories exposed above:

- Trust in message source: Trust is one of the most intuitive aspects involved in communication. If the source of the message is not trusted, the receiver is not likely to take its content into account. In our model, residents have a "trust probability" attribute: it is a table matching each source with a probability to trust the messages it sends: this represents the source's expertise and trustworthiness described in ELM. The values in the trust table depend on the resident's profile. For example, can do defenders have a higher trust in local sources of information than Threat monitors, but a lower trust in firemen. For now, we did not implement source attractiveness, which is also a factor of trust in ELM, as it does not seem very relevant to evaluate trust in official sources in case of a disaster;

- Message acceptance: In order to represent the information overload phenomenon reported in ELM, we added an acceptance probability for each source in the pedestrian attributes, with 
initial values based on the resident's trust in each source. Then, when a resident receives a message, they might accept or reject it based on their acceptance probability for its source; they also subsequently update their acceptance according to the message accuracy and its perceived relevance. Thus, if the message is perceived as inaccurate (too global or imprecise) or useless, the resident's acceptance probability for this source will decrease; on the contrary relevant messages will increase this acceptance probability.

\subsection{Cognitive Biases}

The theories discussed above and implemented in our model provide the agents with a rather rational behaviour, where cognitive evaluation of the source and content of the message might lead to trust and acceptance, and eventually behaviour change. However, human behaviour is rarely purely rational (Kahneman \& Egan, 2011), and even more so in crisis situations such as bushfires (Rhodes, 2014).

\subsubsection{Cognitive Biases Theories}

Message acceptance and behaviour change is also impacted by various cognitive biases, phenomena described in psychology and social sciences that twist reasoning towards "irrational" shortcuts in order to make faster decisions. They are particularly relevant during crises (Yudkowsky, 2008; Kinateder, Kuligowski, Reneke, \& Peacock, 2014) when decisions are made under high stress and time pressure.

Previous studies (Adam \& Gaudou, 2016; Arnaud, Adam, Dugdale, 2017) have found occurrences of these cognitive biases in the population interviews performed after the bushfires (Teague et al., 2009b). For instance:

- The confirmation bias is a tendency to give more credit to information confirming existing beliefs and to discard inconsistent information (e.g. interpret the presence of firemen as a cue that everything is safe in order to confirm motivation to stay);

- Over-estimation of danger to others and under-estimation of danger to self (residents often report they knew there were going to be fires but felt they were not going to be impacted; however, many residents worried for their friends, neighbours and relatives);

- The anchoring effect is an excessive focus on the first information received that prevents from changing one's initial decision even when receiving further (possibly contradictory) information (the authorities report an over-commitment of residents to their defense plan even when the fires were known to be much too strong to be fought);

- The hindsight bias makes people believe that they could (should) have predicted the events (and will predict them next time), which makes them feel guilty for not predicting them;

- The bandwagon effect is doing and believing the same as others around (e.g. residents who think it is safe because their neighbours stay);

- The planning fallacy is underestimating the time something will take (e.g. some residents have been caught by surprise by the fire while still preparing to leave);

- The sunk cost fallacy consists in refusing to abandon a goal even when new information would require it, because of having already invested in it. It is therefore self-reinforcing as more actions are performed to reach the goal (e.g. residents who have invested a lot in building and preparing their house to resist the fires are less likely to abandon it, even when informed they should evacuate).

These biases were shown to impact the residents' behaviour, and it is therefore crucial to take them into account in our model. This will improve the realism of the simulated population behaviour, and ensure that our simulator provides faithful and useful insight. 


\subsubsection{Cognitive Biases Implementation}

We implemented a number of these cognitive biases in our model. For instance, the confirmation bias and anchoring effect are implemented by the fact that the resident's motivation influences their risk assessment and vice versa: a resident motivated to defend will underestimate risk (and discard cues of a higher risk), and low estimation of risk will increase their defense motivation (defense becomes an anchor). The sunk-cost fallacy is implemented thanks to the feedback from actions: the defense motivation gradually increases with successful defense actions, making it harder to give up defense. The planning fallacy comes from the agent's overestimation of their ability: they might start preparing their home, believing they are skilled enough to do so in time, but the fire might come earlier than expected; indeed, objective skills affect their preparation time. Finally, the bandwagon effect is accounted for by the subjective evaluation of danger, which takes into account the behaviour of others around self, and might lead to underestimating danger if others do not evacuate. There is no direct communication between residents however in the current model, only observation of their behaviour.

\subsection{Summary and Evaluation of the Model}

Our model of the population behaviour in reaction to messages is an extension of the Finite-State Machine model initially designed by (Adam \& Gaudou, 2016). We implemented concepts from various sociological and psychological theories in order to take communication between authorities and population into account. Communication inside the population is not implemented here, but is dealt with in other work (Adam \& Dugdale, 2018).

In order to validate this theoretically-grounded model, we ran simulations with the communication strategies reported (and criticised) in the residents' interviews (concretely: broadcast of general information) and found that the generated behaviour of the population was consistent with that described in the interviews. Indeed, they mostly discarded messages and adopted a 'wait and see' attitude, unless they were already highly motivated either to stay or to defend. This means that the general broadcast informative messages had little impact on behaviour change. More detailed experiments are described in the following section.

\section{EXPERIMENTS AND RESULTS}

This section presents our first experiments with this model. Our goal here is to show that by using our simulator, someone can gain insight about relative effectiveness of different communication strategies on different people. Below we define different profiles of residents (who will have different reactions to messages); we then describe the scenarios that we tested, as well as the indicators used to measure success of the compared strategies; we finally discuss our first results.

\subsection{Profiles of Behaviour in the Population}

\subsubsection{Behaviour Profiles}

(Rhodes, 2014) has extracted 6 behaviour profiles of the population in bushfires:

- Can do defenders: Skilled and experienced defenders, relying nearly only on their own abilities to manage the situation;

- Considered defenders: Good defenders with several possible plans to deal with fires; they are more likely to listen to warnings from the authorities than Can do defenders;

- Livelihood defenders: Will protect their property whatever the danger, because it is their source of income;

- Threat monitors: Focused on defense but will immediately escape if they feel a real danger;

- Threat avoiders: Focused on escape, will decide to run away as soon as they are aware of fires;

- Unaware reactors: Do not feel concerned by fire risk, and do not known how to react in case of a fire. 


\subsubsection{Distribution of Profiles}

However, (Rhodes, 2014) provides no information about the distribution of these profiles in the population, and states that they are not linked with demographic features. In their simulator, (Adam \& Gaudou, 2016) have shown that the distribution of these profiles is indeed dynamic, and differs based on the seriousness of the fires. They did not implement the profiles, but measured behavioural features in order to dynamically categorise agents in the different profiles. We adopt a different approach here, where we do actually implement agents with different pre-set profiles of behaviour, in order to be able to compare the impact of the communication strategies on these different profiles. Our goal is to allow targeting strategy towards the profile of the receiver, based on Rhodes' findings.

\subsubsection{Implementation of Profiles of Behaviour}

We implemented the different profiles of behaviour in terms of ranges of values of their attributes, and modified transitions in the finite-state machine. For instance, livelihood defenders cannot escape but are more likely to shelter if needed; they also have a high ability to fight fire and a high trust in local sources. The type of population can be selected as a simulation parameter. Agents are then initialised with random values of their attributes selected in the pre-set range determined by their profile.

\subsection{GAMA Experiments}

\subsubsection{Experiments}

GAMA allows 2 types of experiments:

- Graphical experiments: Run one simulation and observe the behaviour of the agents "live" to have a quick overview of their reaction to various strategies (see screenshot on Figure 2);

- Batch experiments: Automatically run many iterations of each simulation (with the same parameters). In that case there is no graphical display but GAMA output graphs of the average values (over all iterations) of selected indicators, which is a standard technique that allows smoothing out the randomness of the simulation.

\subsubsection{Scenarios}

Based on our analysis of the interviews, and on the theories modelled in our simulator, we have designed 4 scenarios that allow comparing the different dimensions of communication.

Scenario 0 is our baseline: we compared the values of all indicators on the two populations without any communication. This is used for a sensitivity analysis purpose: we checked that the different profiles showed different behaviour in the absence of communication, and that communication did have the expected impact on them.

Scenarios 1 and 2 isolate and analyse the different dimensions of messages. The first dimension is the content of messages, which were mainly informative during the 2009 bushfires according to the interviews; the population regretted not getting more recommendations, so we compared these 2 options in scenario 1 . The second dimension is the target of messages, and specifically the accuracy of this target. According to the interviews, residents mainly received generic broadcast messages, while they expected something more personalised; so, we compared various levels of accuracy (broadcast vs geographical-targeted vs plan-targeted) in scenario 2 .

Scenario 3 is a bit different. In an attempt to prove the usefulness of our simulator, we explored the impact of shelter-based strategies, not reported in the interviews, to show what insight can be gained.

\subsubsection{Compared Profiles}

Our simulator aims at showing how understanding the population can improve communication to them. We therefore compared the impact of communication strategies on different profiles of residents. The 
goal is to show that different profiles will react differently to the same message, which supports the requirement for more personalised communication to have more impact on the population.

Concretely, we have run experiments to compare the strategies above on 2 profiles of population out of the 7 listed by Rhodes, namely the can-do defenders (planning to defend their property and skilled to do so) and the threat avoiders (planning to escape fires). Indeed, these are the two extremes in the scale of profiles, which makes the differences most visible. We expect the other profiles to fall somewhere in between these two markers in terms of communication needs. More detailed experiments can be performed in future work to further investigate these precise differences, but the point of the current paper is just to prove that our tool allows to show and explain such differences.

\subsubsection{Indicators}

To be able to compare the different strategies, we defined and implemented the following indicators measuring their relative success or failure: number of deaths; number of injuries; total damage to houses; total cost of communication actions.

\subsubsection{Settings}

For each scenario (comparing several simulations), we ran 60 iterations of 200 cycles of each simulation (which represents over 3 hours of simulated time with one minute long cycles). Between the compared simulations, we only varied the communication strategy tested, with the other parameters being exactly the same (number and strength of fires, population, availability of communication channels, etc.).

\subsubsection{Output}

The output of our batch experiments consists in graphs showing the comparative average values of these indicators for different strategies over the 60 runs. Averaging values is a standard technique to smooth out the inherent randomness of the model (initial location of fires, propagation, initial features of individual residents, etc.). It is therefore the most relevant statistical value. The graphs obtained for the scenarios defined above are discussed below.

\subsection{Scenario 0: No Communication}

We first compared the impact of fires on the two populations when no communication actions are performed. With the threat avoiders, population is focused only on escape, and since we did not implement firemen in our simulation, we expected the fires to grow out of control and lead to a high number of victims and great amount of damage. There was indeed a huge gap (in terms of damages, injuries and deaths) compared to the can-do defenders population, as shown in Figure 3.

The next scenarios compare the impact of various communication strategies on these two populations.

\subsection{Scenario 1: Comparing Information vs. Recommendation Messages}

\subsubsection{Can-Do Defenders}

As expected with such skilled defenders, values of building damage, injuries and deaths are quite low. As shown on Figure 4, there are no big differences between broadcasting fire information and recommendations in terms of damage or cost. There are slightly more injured and dead with recommendations only. Our data allows explaining this observation: in the absence of information messages, many residents remain unaware of the fires (too far to be perceived directly) so they do not feel concerned and ignore recommendations. As a result, they do not prepare and end up being more vulnerable when the fire arrives. Since less people defend, the fire grows faster and later blocks or injures escapers. On the contrary with information only, residents are aware of all fires even far away, which increases their subjective risk perception and in turn influences their behaviour: more 
Figure 3. Comparing can-do defender and threat avoider populations - no communication

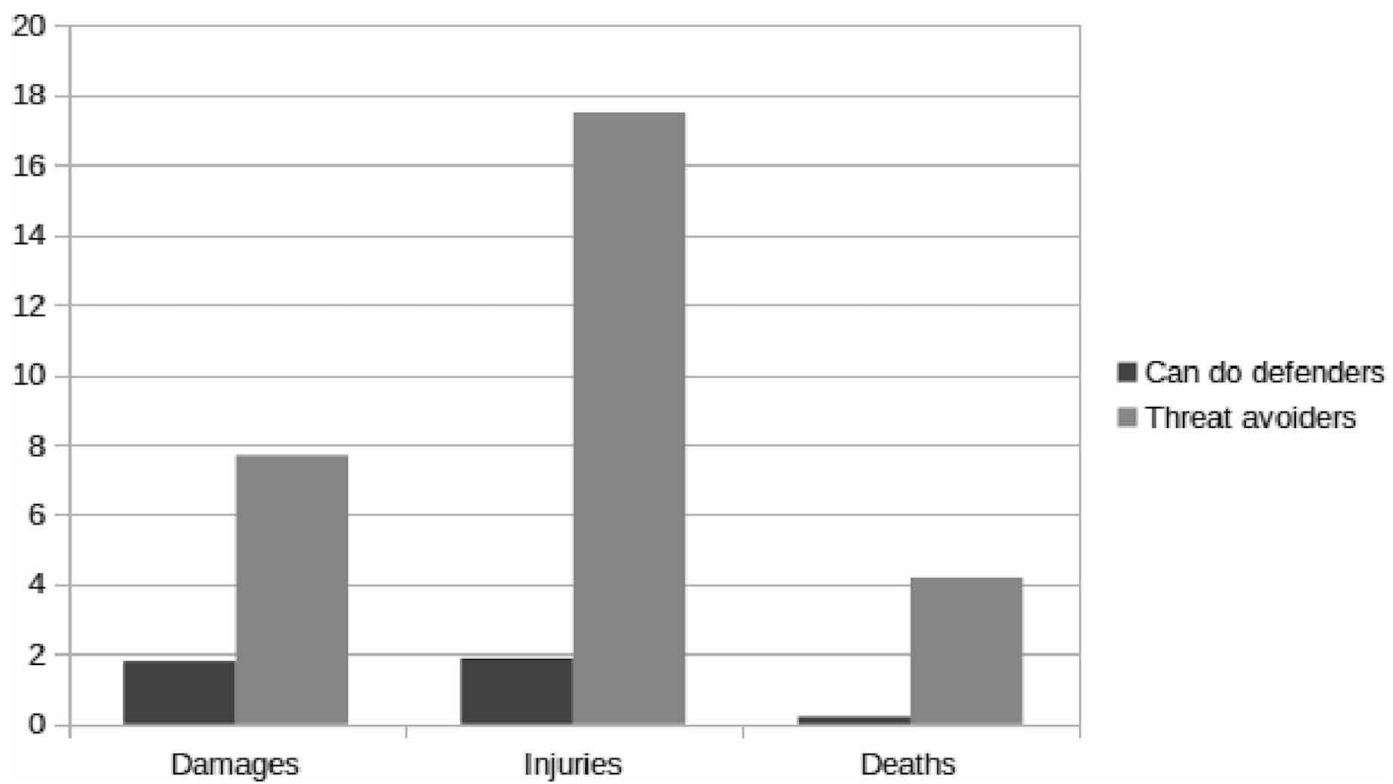

people escape early and stay safe. The difference between the two strategies remains small because can-do defenders rely mainly on themselves rather than the authorities, so they are less likely to accept the messages anyway.

\subsubsection{Threat Avoiders}

The difference between information and recommendations is much more visible on threat avoiders since they are more likely to accept messages (Figure 5). With the information messages, there are more escapers and less defenders because of danger perception distortion (knowing more fires leads to overestimating danger), and therefore more damage to buildings. Furthermore, threat avoiders have a lower capability than can-do defenders, their escape will be less efficient so they are more likely to get hurt, leading to more injuries. Recommendations are therefore more efficient than generic information.

\subsection{Scenario 2: Accuracy of Messages}

\subsubsection{Can-Do Defenders}

The accuracy of messages has a more significant impact than their content on can-do defenders. Broadcasting is the worst strategy, geographical targeting the best but most costly, and plan-based targeting is a compromise (Figure 6). Contrary to what one might think, message acceptance is not the major factor here (can-do defenders are skilled, so they can make good survival decisions even if rejecting most messages). What matters most is the number of escapers: again, broadcasting all fires to all residents leads to overestimation of danger, encouraging more residents to escape. Can-do defenders are somewhat protected against overestimation of danger due to their lower trust in messages and higher ability to observe the fires, but we still observed about half of the population escaping and half defending. On the contrary, with geographically targeted communication people are informed only about fires close to them and therefore have a more accurate perception of immediate danger. As a result less residents decide to escape without being in real danger, so they are more likely to protect their home and avoid damage and injuries. 
Figure 4. Comparing impact of content-based strategies (Information vs. Recommendations) on can-do defenders

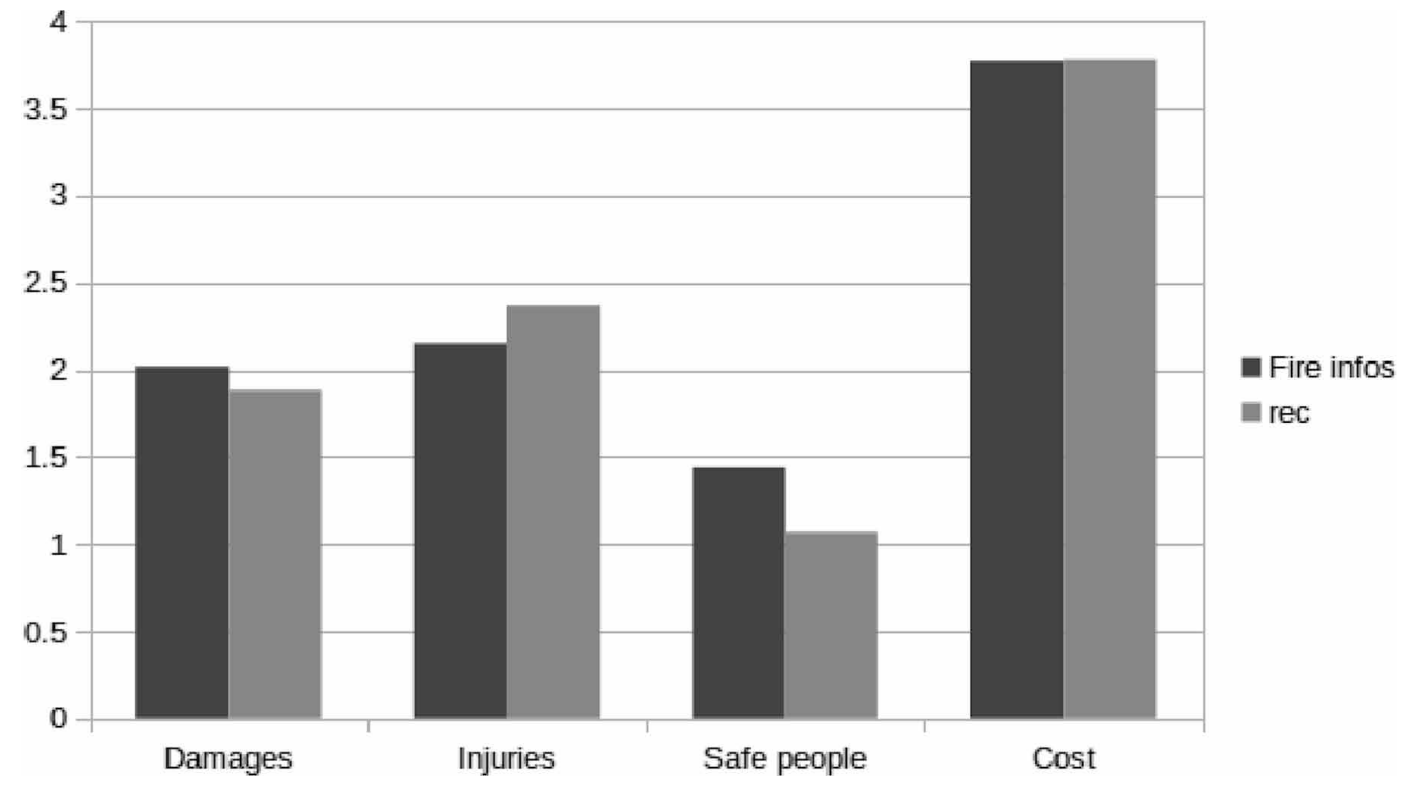

Figure 5. Comparing impact of content-based strategies (Information vs. Recommendations) on threat avoiders

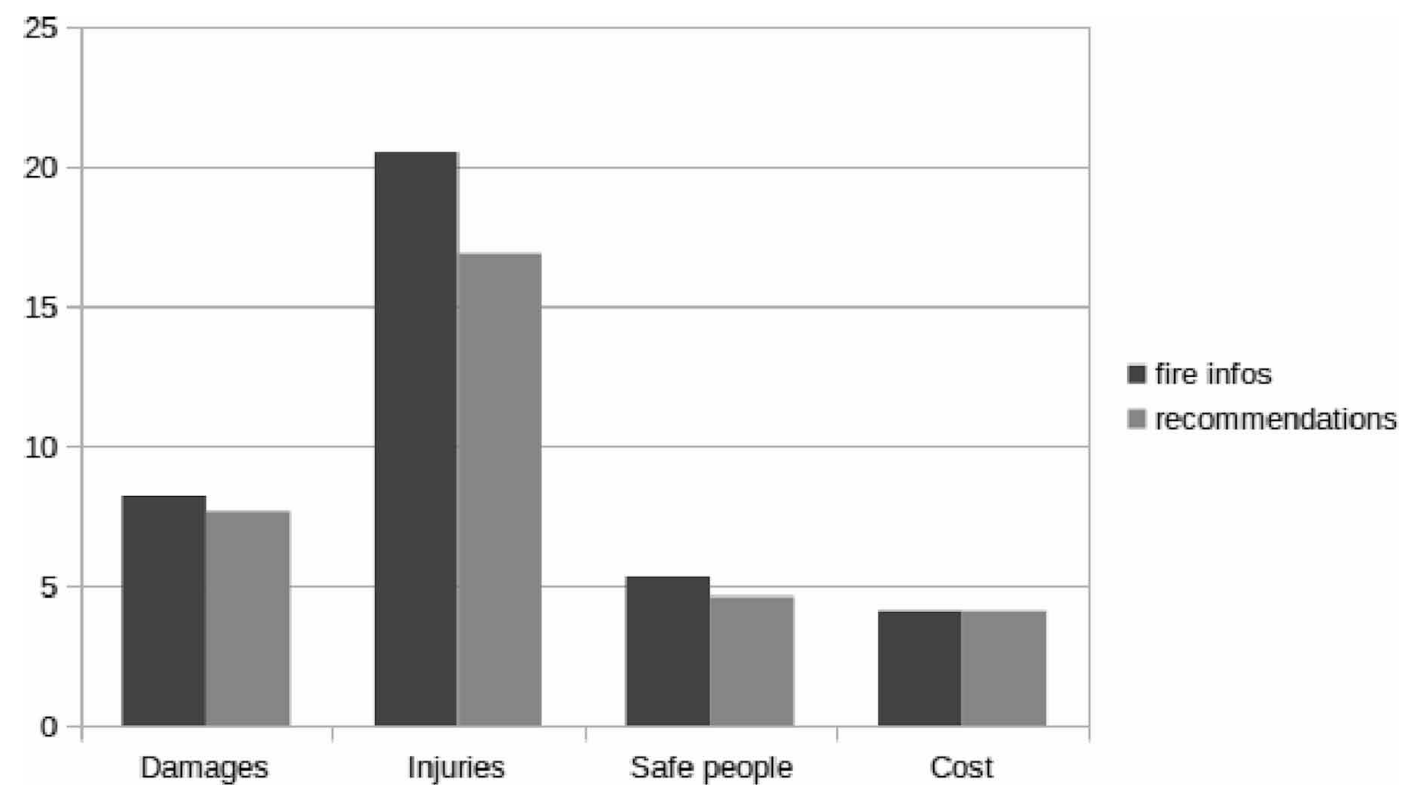

\subsubsection{Threat Avoiders}

Not surprisingly, the most efficient strategies are the same as for Can-do defenders (targeted communication is better than broadcast), even though the values of the indicators (damage, injuries) are much higher here (see Figure 7). This is because threat avoiders are more likely to accept and react to the messages even when not directly concerned (fires too far), and more likely to overestimate 
Figure 6. Comparing impact of target-based strategies on can-do defenders

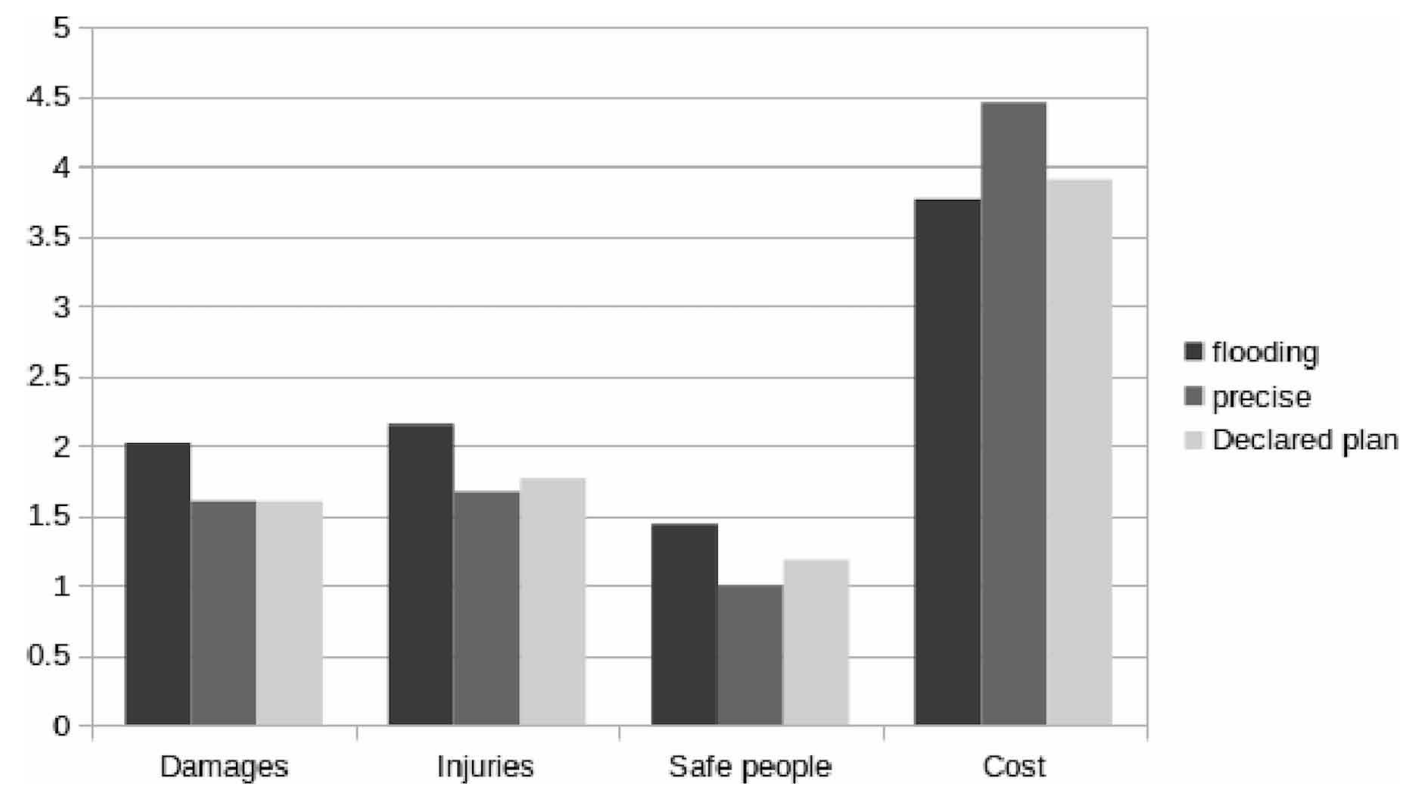

danger due to their lower ability to judge by themselves. As a result, we observed much more escapers and less defenders in this population. Therefore, less people fight the fires, resulting in more damages to buildings, and the fires grow bigger, injuring more escapers.

\subsection{Scenario 3: Shelter Communication}

The goal here was to compare the efficiency of two opposite strategies: building more shelters but without informing people about them, or relying only a few shelters but advertising a lot about them. Both strategies aim at making sure that all residents know where to escape if needed.

\subsubsection{Can-Do Defenders}

We observed no real difference between these 2 opposite strategies on can-do defenders (see Figure 8 ). Communication is only slightly better but much less costly than building new shelters. This is not really surprising. Can-do defenders are skilled and experienced and therefore know the position of the shelters already (even if there are only few of them) and can reach them easily. Moreover, most of them decide to stay and fight against fires anyway, making shelter-based strategies irrelevant to them. Finally, with more defenders, there is less congestion on the roads to the shelters and the fire does not propagate so fast, so the escapers are more likely to reach the shelters uninjured.

\subsubsection{Threat Avoiders}

Shelter-based strategies have a much more differentiated impact on threat avoiders (see Figure 9). The first thing we can notice is the difference in terms of safe people. Threat avoiders have lower abilities to react to fires, and may not know the position of shelters or not be able to quickly reach them. When building more shelters rather than advertising them, some residents do not know any safe area and just run randomly to avoid fires, leading to more injuries and less safely sheltered people. The longer the simulation time, the bigger the fire grows, and the more randomly running people get trapped. However, the damage is slightly lower in that case as some residents, not knowing where to go, end up sheltering in their own house and defending it. Advertising the existing shelters reduces the time spent on roads looking for one, and therefore the number of injuries incurred by escapers. 
Figure 7. Comparing impact of target-based strategies on threat avoiders

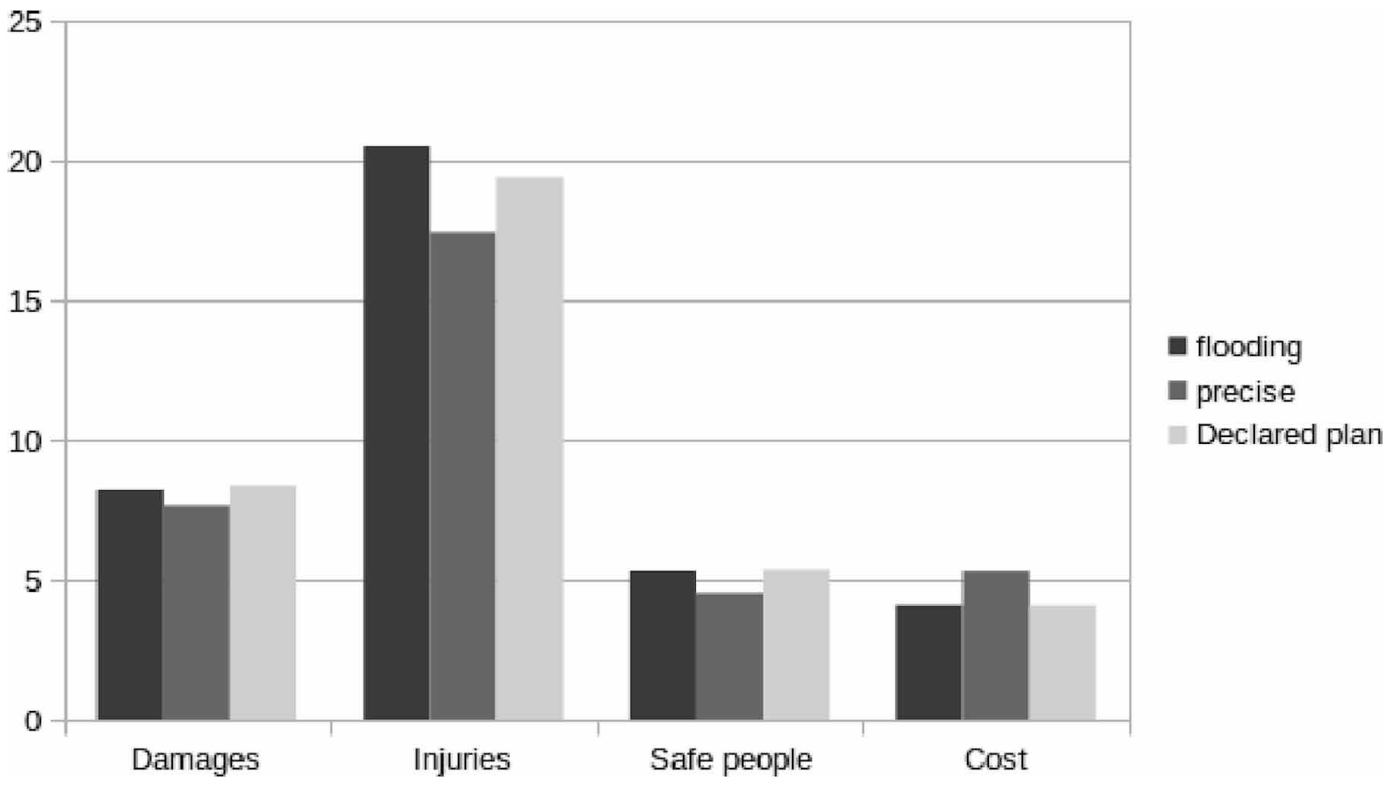

Figure 8. Comparing impact of shelter-based strategies on can-do defenders

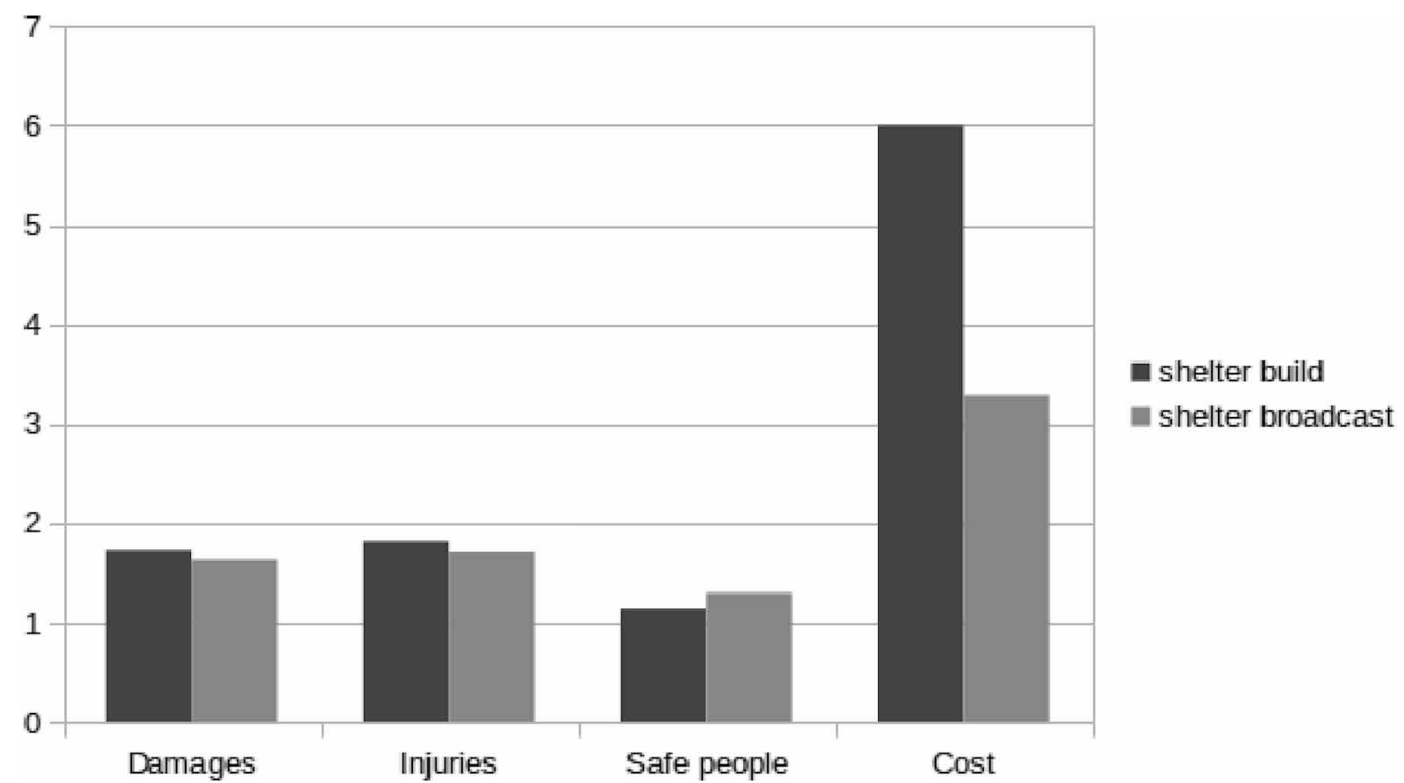

Of course, these are the two extreme strategies (building only vs communication only) and we expect the best strategy to lay somewhere in the middle, with a balanced compromise of having enough safe areas and making sure everybody is aware of them. 
Figure 9. Comparing impact of shelter-based strategies on threat avoiders

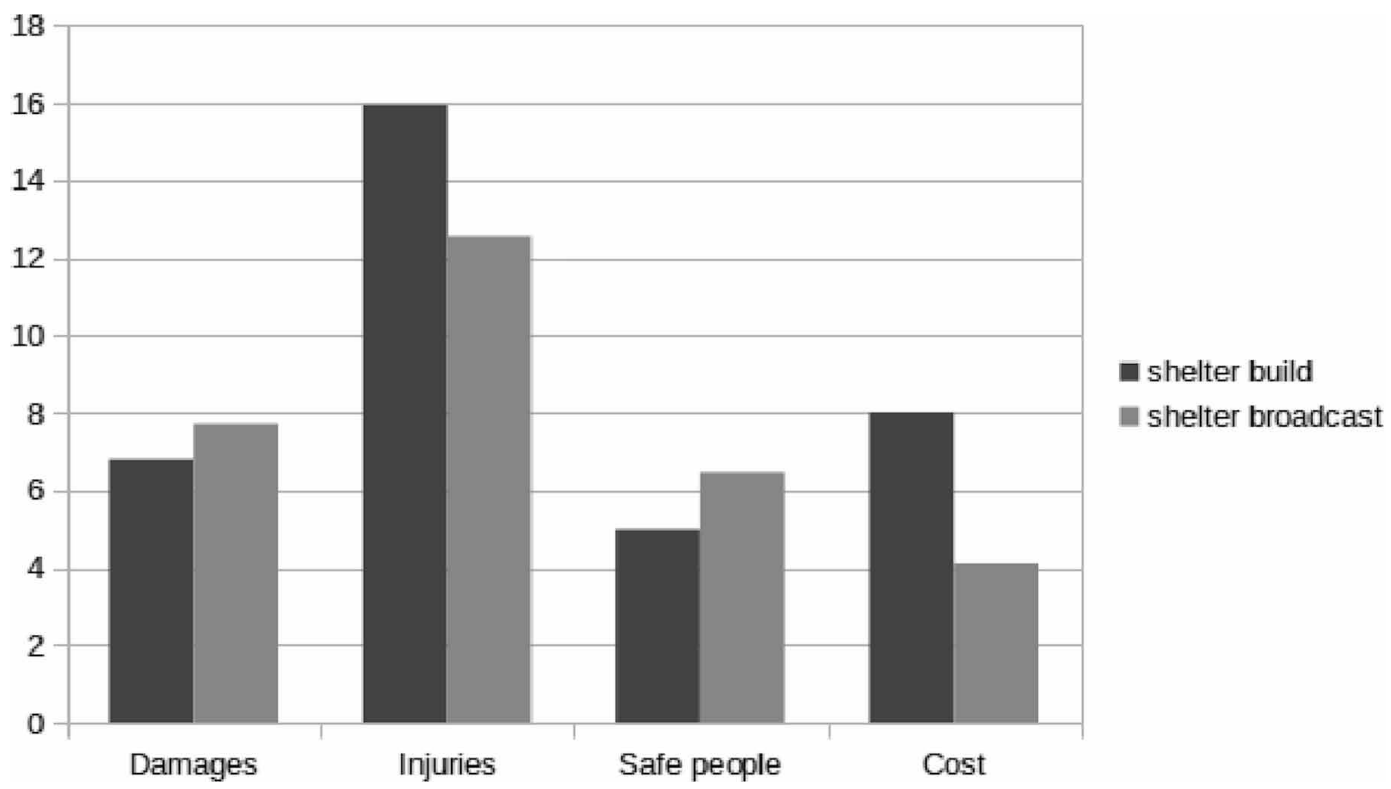

\section{DISCUSSION}

\subsection{Personalisation to the Profiles}

As expected, communication should be personalised to the different profiles found in the population (or at least to broader categories of defenders vs. escapers), in order to provide each resident with information that is relevant and helpful to them without drowning it in a flow of irrelevant messages.

Our results show that the best communication strategy towards can-do defenders is to inform them about fires in their geographical area. Its downside is its high cost (the smaller each target area, the more different messages need to be elaborated and sent), so targeting residents based on their declared plans may also be a good and less costly alternative. Messages about safe areas are secondary for intended defenders and should be used parsimoniously.

Accurate geographical targeting is also better for avoiders (even though more costly), but contrary to defenders recommendations are more useful for them than bare information, as they are not skilled enough to interpret the latter. Moreover, early information about shelters is useful to raise awareness of escape possibilities and trigger earlier evacuation, thus reducing injuries incurred while escaping.

\subsection{Plan-Based Targeting}

For the plan-based broadcast strategy, we assumed that residents had previously declared their fire plan (intention to defend or to leave) to the fire authorities. This is not the case in reality (in these scarcely populated areas, the fire brigades might have some information but not necessarily about everybody); however, experimenting with this strategy allows us to show what could be done if the population was asked for their fire plan in advance and therefore still provides valuable insight.

Besides, it also shows the interest of indirect communication: global authorities might not know each resident's fire plan when broadcasting messages, but local managers might do. They could act as a filter between the large-scale broadcasting and their local residents, receiving all messages and only forwarding the most adapted ones for each resident. Of course, this is also a costly strategy, but automation could be investigated. 


\subsection{More Experiments Needed}

A big limitation of our experiments is that they are all performed on a homogeneously profiled population in order to draw relevant results for that population. However, in reality, the population is heterogeneous with residents of all 6 profiles listed above, and a continuous range of motivations and abilities. Strategies are yet to be tested on a population with a realistic distribution of these profiles, but we first need to obtain data about what this distribution is in the actual population.

We also tested all strategies independently, while in reality emergency managers may use a combination or sequence of several strategies, for instance broadcasting information and recommendations at the same time. More experiments are yet to be conducted with more realistic combined strategies, possibly in cooperation with emergency managers.

Finally, our experiments were quite short: 200 cycles of simulation means about 3 hours of simulated time. In reality these fires can last for days. Longer-term communication strategies thus need to be tested as well, to ensure residents stay out of affected areas, respect possible roadblocks, etc.

\subsection{Simplification}

A model always ought to be a simplified version of reality. There are however a number of improvements that could be made in future work to improve the realism of our simulation. Of course, the random fire model is the first thing that comes to mind; it should be replaced with a realistic model of fire taking physical and meteorological parameters into account (wind strength and direction, rain, temperature, etc.) when computing propagation and growth. Such models already exist (Miller, Hilton, Sullivan, \& Prakash, 2015).

Of more interest to us are the agents involved in the simulation. So far we only modelled residents as autonomous agents, and emergency managers are "played" by the user but can only send messages. It would be very interesting now to also model firemen and their different actions on the field, from fighting the fire to communicating with the population and helping them. The only presence of firemen also has a great psychological impact on residents (Kinateder et al., 2014), which should be modelled.

\subsection{Goal of This Simulator}

However, we remind that our goal in this paper is not to determine which strategy is 'optimal', but to provide a tool to improve mutual understanding. So far we have looked at improving the stakeholders' understanding of the population. For this understanding to be mutual, we will now look at improving the population's understanding of the challenges faced by the stakeholders. In order to involve the general public into our tool, we have studied how to turn it into a serious game.

\section{TOWARDS A SERIOUS GAME}

According to (Roberts \& Lajtha, 2002), “...the key to effective crisis management lies not so much with the writing of detailed manuals (that have a low likelihood of being used) and practicing location evacuations, as with structured and continuous learning processes designed to equip key managers with the capabilities, flexibility and confidence to deal with sudden and unexpected events..." As discussed above, serious games do offer benefits for crisis management, and in particular this possibility of continuous learning by engaging the learner in a playful yet serious process aimed at letting them explore and discover best practices and strategies. There have therefore been many works to use serious games in the field of crisis management (see (Di Loreto, Mora, \& Divitini, 2012) for a survey), in particular regarding communication training (Haferkamp et al., 2011).

In this article so far we have developed a realistic simulation of the population, including psychological aspects of their behaviour, and interactive user actions simulating various communicative actions. This simulation is aimed at providing professionals with a decision-support tool for improving 
communication strategies during bushfires; it is interactive, but it is however still far from a serious game able to engage the general public and raise their awareness.

In the section below: we first discuss the use of interactive simulation for raising awareness; we then survey some relevant literature about user engagement and motivation, and about gamification and how it can create this engagement; we then describe a successful example of turning an agentbased simulation into a serious game; and we finally discuss the steps needed to turn the current simulation into a proper serious game.

\subsection{Participatory and Interactive Simulation for Raising Awareness}

Computer simulation is a great tool for crisis management (Urban \& Oulehlová, 2017; Dugdale et al., 2010; Radianti et al, 2015; Kleiboer, 1997), which offers many benefits. Compared to full-scale simulation exercises, it is much less costly, less dangerous, and easier to organise. Yet it still allows discovering knowledge by exploring several "what-if" scenarios before an actual crisis happens, with complete control on all parameters. Participatory simulation is a type of simulation where human users interact with the simulated world by controlling some of the agents in the system. Participatory simulation is therefore a type of serious games, i.e. games that are used not for entertainment but for learning, training, or understanding mechanisms (Michael \& Chen, 2006).

Serious games have several benefits over more classical approaches to teaching or raising awareness. They follow a constructivist logic in which the players build their own knowledge by confronting a problem in a simulated world. A meta-analysis gathering 193 articles about serious games (Sauve, Renaud, \& Gauvin, 2007) has shown many benefits such as: favouring the development of social and human relationships and communication skills; increasing learning motivation, selfesteem and self-confidence, engagement and persistence; developing problem-solving skills; helping learners to structure, build and represent knowledge; and helping learners to integrate information by developing the capability to build links and transfer knowledge from other contexts.

Interactive simulations and simulation-based serious games are particularly interesting for raising awareness of various types of risks (Benjamins \& Rothkrantz, 2007; Crovato et al., 2016). By being placed in a risky situation and allowed to try several ways of managing it, the players can better comprehend the risks and their possibility of occurrence, but also the consequences of their actions of these risks. For major risks such as bushfires, exploring different strategies and their impact in a serious game provides players with some experience, simulated but close to the real-world mechanics. Such experience would be hard to acquire from real crisis in such a short time, due to the long duration between events (several months to years), and the stakes involved that prevent from trying blindly. An important aspect of serious games and participatory simulations is to rely on a pedagogical scenario integrated in the game design to answer a specific pedagogical objective (Chadli, 2015). Moreover, a number of well-specified rules must guide the player's experience by specifying objectives, conditions of victory or failure, possible interactions with the game and the other players (if any), and mechanisms for the evolution of the game world. These rules can be integrated in the computer model, provided externally (e.g. note card to be referred to when needed), or both.

\subsection{User Engagement and Motivation}

Two forms of motivation are usually opposed as the two extremes of a continuum (Vallerand, 1993): intrinsic motivation (internal motivation to do something because of its pleasantness or subjective importance or significance) and extrinsic motivation (external factors or rewards pushing to do something, e.g. to gain money). Intrinsic motivation however is more likely to lead to long-term engagement. In the paragraphs below we describe models of these two notions: Karasek's model of engagement, and Marczewski's RAMP model of intrinsic motivation.

(Brandtzaeg, Folstad, \& Heim, 2006) studied "funology", i.e. enjoyment in human-computer interaction, by using Karasek's model of engagement and well-being at work. They found that the same three factors influenced engagement in both computer games and work: 
- Demands on the worker or player (challenge and surprise but not overwhelming);

- Level of control they have (controlled interaction, timely feedback);

- Support they receive (social interaction with peers).

(Marczewski, 2013b) has proposed the RAMP model that breaks down intrinsic motivation into 4 dimensions:

- Relatedness (social factors, interactions with colearners, feeling part of a community);

- Autonomy (feeling of having choice and freedom);

- Mastery (incremental learning of skills, progressive achievements, challenge tailored to current skill level);

- Purpose (relevance and meaning of the content learned, knowing why it is taught).

The dimensions in the two models are quite similar: autonomy vs control, relatedness vs support, mastery vs demands; only the purpose dimension in the RAMP model was neglected in Karasek's model, maybe because it was less relevant in work situations than it is in games. In the sequel we look at how motivation or engagement can be elicited in the user.

\subsection{Gamification and Gaming Design}

\subsubsection{Definition}

The most widely-used definition of gamification was given by (Deterding, Dixon, Khaled, \& Nacke, 2011) as: "the use of game design elements in non-game contexts, products, and services to motivate desired behaviors". It is however criticised because of the uncertainty about what constitutes "game design elements", and because not everything that does include game design elements is gamified. (Werbach, 2014) has then defined gamification not based on game elements but as "the process of making activities more game-like," and relates it to persuasive processes. An activity can therefore become more or less game-like, rather than being considered as gamified or not. Indeed, many game designers have criticised the current implementations of gamification, often limited to "adding points, badges, and leaderboards to mundane user activities," as "taking the thing that is least essential to games and representing it as the core of the experience" (Deterding, 2012). Then (Huotari \& Hamari, 2012) insist on the fact that gamified applications should invoke the same psychological experience as games.

\subsubsection{Applications}

Gamification is therefore used to favour engagement in many fields, for instance health, or education, for instance in e-learning systems (McGinnis, Bustard, Black, \& Charles, 2008).

(Hamari, Koivisto, \& Sarsa, 2014) reviewed 24 studies about gamification, along a conceptual framework considering both motivation, psychological outcomes, and behavioural outcomes. Their conclusion is that gamification does indeed work, but its efficiency greatly depends on the context (is the system being gamified utilitarian or hedonic, does it involve its users cognitively or affectively) and the users. Indeed, there exist different player types and therefore different gamification user types (Marczewski, 2013a). For instance, the use of external rewards can motivate some, but undermine intrinsic motivation in others; some users also dislike competition while it is a powerful driver to others.

But with gamification being also used in professional contexts, there is debate about it being a form of exploitation (Bogost, 2011), since it is manipulating users to adopt desired behaviours or to disclose personal data. A code of ethics of gamification is therefore needed (Shahri, Hosseini, Phalp, Taylor, \& Ali, 2014). 


\subsubsection{Conclusion}

To conclude, what we will call gamification here is the use of game design elements in order to turn our interactive simulation into a more engaging and playful experience. In the next paragraph we further illustrate this process by describing a successful example of turning an agent-based simulation into a serious game.

\subsection{A Successful Example}

Taillandier et al. (Adam, Taillandier, Delay, Plattard, \& Toumi, 2016) have proposed an agent-based simulation for raising awareness about coastal flood risk on the Oleron Island, which they later turned into a serious game now used for teaching risk management at the University of Bordeaux (Taillandier \& Adam, 2017).

In the SPRITE simulation, the user plays the role of the mayor of the island who can use various actions (build dykes, expropriate residents, promote ecology, etc.) to improve the safety and global satisfaction of their residents. In the gamification process of the SPRITE simulation, the authors added the following game design elements:

- Budget: Actions are constrained by a limited budget, which the player can increase by changing the tax rate, but with the risk of losing residents; this contributes to challenging the player;

- Elections: Every 5 years, the residents vote for their new mayor; being reelected requires the player to strike a good balance between various indicators such as safety, ecology, etc., which is a skill to be learnt incrementally;

- Feedback: An interactive map allows the player to see the current state of the island as well as previous submersions, and the console also displays immediate and useful feedback about cost and remaining budget;

- Scenarios: Different pedagogical scenarios of different difficulties can be selected, having different purposes; for instance, one scenario will first encourage the player to satisfy their residents (building houses by the sea, etc.), before triggering a big submersion to let them discover the importance of a more balanced management of the island (avoiding building houses in unsafe areas, etc.);

- Interactions: The game is played in pairs of students who discuss their choices together; the final score is converted into a qualitative value (good, very good, average, etc.) to help assessing the results; and an online high-score table also allows comparison with other players;

- Pedagogical sequence: The game itself is preceded by an introduction, and followed by a debriefing and an actual course about risk management; this makes the game an integral part of learning, and helps the students grasp the purpose of what they are learning.

After having played this serious game during their risk management course at University of Bordeaux, the students answered a questionnaire. The first results showed that the game was evaluated positively, as being immersive and helpful to learning.

This example provides us with an interesting illustration and inspiration regarding the type of components that can help making an interactive simulation more interactive and engaging for the player.

\subsection{Turning SWIFT Into a Serious Game}

In this section we provide a specification of the gaming elements to be integrated into this simulation to turn it into a serious game. This specification is inspired by the successful example of SPRITE as well as the theories of engagement and motivation described above. We sort our proposed gaming elements in paragraphs corresponding to the motivational factors they contribute to. 


\subsubsection{Autonomy, Control}

- Interactive map and console: SWIFT should provide the player with useful feedback on the map and in the console; for instance, we intend to offer a display showing the propagation of information in the population depending on the selected strategy;

- Success indicators: An important part of feeling in control is getting meaningful feedback; we will define significant indicators, such as the time needed for all the population to be aware;

- Pedagogical scenarios: SWIFT should offer various scenarios where the user can select what skill they want to learn.

\subsubsection{Mastery, Demands}

- More varied actions: We intend to add other actions than just communication strategies, to add variety and challenge to the game. For instance, other envisaged actions consist in dispatching police or firemen crews; closing roads; requisitioning a building to turn it into a shelter;

- Action cost: Each action should cost something (in money, manpower, and/or time), therefore limiting the actions that the player can perform at each turn;

- Limited time: We could also use a timer to constrain the decision time and put the player in a similar state of stress as in a real emergency.

\subsubsection{Relatedness, Support}

- Multi-player cooperation: A key aspect in crisis management is the necessity to collaborate with various organisations (firemen, police, mayor, etc.). We aim to add different roles in the SWIFT game and let different human users play these roles to try and reach good collaboration;

- Debriefing: Almost as important as the game is its debriefing, where the players can discuss their experience with the game.

\subsubsection{Purpose}

Finding purpose in their training may seem more obvious for professional crisis managers than classical students, who are often the target in the works described above. However, we intend our serious game to be also used by the general public. Therefore, a pre-game introduction will present the results that led to the creation of this game, in particular the existing mismatch between the population's expectations regarding communication and the messages that were actually sent by the authorities during the 2009 bushfires. As shown by the example of SPRITE above, to maximise efficiency the serious game must be part of a complete pedagogical sequence.

Some of these elements were already added in (Adam \& Dugdale, 2018), but most remain to be implemented. This will be the focus of our future work.

\section{CONCLUSION}

\subsection{Summary}

In this paper we described our extension of an existing simulation of the Australian population in bushfires. The underlying simulation was validated against real data obtained mainly from residents' interviews after the 2009 bushfires (Adam \& Gaudou, 2017). Concretely, we enriched the residents model to allow them to handle messages, and modelled several psychological processes that influence this handling; this theoretically-grounded model was evaluated against actual behaviour as described in interviews. We also added interactive functionality for the user to test various communication strategies on this simulated population. 


\subsection{Results}

Finally, we ran batch experiments to highlight the pros and cons of different possible strategies on different profiles of residents, and deduced some useful insight for emergency managers. These first experiments were mainly intended as a proof of concept of our simulation as a decision-support tool for managers: they show that it allows visualising impact of different strategies on different populations. In the future we will implement more complex strategies to allow more varied experimentations: choice of channel, temporal composition of messages, indirect communication through local representative, etc.

\subsection{Future Work}

In particular, we intend to dedicate some future work to the following aspects. First, we will model a more realistic population, with a heterogeneous distribution of the different profiles, and also with social relationships and attachment between the agents (Bañgate, Dugdale, Adam, \& Beck, 2017). Second, we will go deeper in the formalisation of cognitive biases (Arnaud et al., 2017); here we focused only on a few of them that affect message handling, but many others play a role in disaster reactions; other interesting psychological factors at play in such situations include emotions. Also, we want to more deeply study trust (in the source and channel), its impact on behaviour change, and its dynamic. Finally, the communication model could also be enriched; in particular we want to add more possible message types and contents: promissives and expressives might be relevant, for instance expressing fear about the situation, or promising that the fires are under control; FIPA-like messages have been used in other works such as (Mancheva \& Dugdale, 2016), who modelled communication inside a medical team.

\subsection{Generalisation}

Since our model is grounded on theoretical literature about communication, it is not specific to bushfires and can be extended in the future to other types of disasters. What will need to be adapted is only the domain-specific content of the messages. The general structure of the game will however remain the same. This could be very interesting to study similarities and differences in communication during different types of disasters.

\subsection{Serious Game}

Finally, as discussed extensively above, we intend to gamify this simulation, i.e. to turn it into a serious game that will foster engagement of its users. Starting from the specification of gaming elements performed in this paper, we will incrementally implement such elements, and validate their effects on the users. It is important to notice that such work is generic and can be applied to different types of disasters, as shown by the SPRITE serious game for raising awareness about coastal floods risk (Adam et al., 2016). We believe that agent-based modelling and simulation is a great tool to raise awareness and prepare crisis management plans for any types of crisis, be they natural disasters or man-made events. 


\section{REFERENCES}

Adam, C., \& Dugdale, J. (2018). Agent-based analysis of the spread of awareness in the population in the prodromal phase of bushfires. In Proceedings of the 51st Hawaii International Conference on System Sciences. doi:10.24251/HICSS.2018.010

Adam, C., \& Gaudou, B. (2017). Modelling human behaviours in disasters from interviews: Application to Melbourne bushfires. Journal of Artificial Societies and Social Simulation, 20(3), 12. doi:10.18564/jasss.3395

Adam, C., Taillandier, P., \& Dugdale, J. (2017). Comparing agent architectures in social simulation: Bdi agents versus finite-state machines. In Hawaii International Conference on System Science (HICSS), Kona, HI. doi:10.24251/HICSS.2017.032

Adam, C., Taillandier, F., Delay, E., Plattard, O., \& Toumi, M. (2016, October). SPRITE-Participatory Simulation for Raising Awareness About Coastal Flood Risk on the Oleron Island. In International Conference on Information Systems for Crisis Response and Management in Mediterranean Countries (pp. 33-46). Cham, Switzerland: Springer. doi:10.1007/978-3-319-47093-1_4

Arnaud, M., Adam, C., \& Dugdale, J. (2017, May). The role of cognitive biases in reactions to bushfires. In ISCRAM, Albi, France.

Austin, E. W., Pinkleton, B., \& Fujioka, Y. (1999). Assessing prosocial message effectiveness: Effects of message quality, production quality, and persuasiveness. Journal of Health Communication: International Perspectives, 4(3), 195-210. doi:10.1080/108107399126913 PMID:10977288

Bañgate, J., Dugdale, J., Adam, C., \& Beck, E. (2017, May). A review on the influence of social attachment on human mobility during crises. In Iscram. Albi.

Benjamins, T., \& Rothkrantz, L. J. M. (2007). Interactive simulation in crisis management. In International Conference on Information Systems for Crisis Response and Management (ISCRAM).

Bogost, I. (2011). Persuasive games: Exploitationware [Gamasutra]. Retrieved from https://goo.gl/Q5FwfC

Bonabeau, E. (2002). Agent-based modeling: Methods and techniques for simulating human systems. Proceedings of the National Academy of Sciences of the United States of America, 99(Supplement 3), 7280-7287. doi:10.1073/ pnas.082080899 PMID:12011407

Brandtzaeg, P. B., Folstad, A., \& Heim, J. (2006). Enjoyment: Lessons from karasek. In M. Blythe, K. Overbeeke, A. Monk, \& P. Wright (Eds.), Funology: From usability to enjoyment (Vol. 3, pp. 55-65). Netherlands: Springer. Retrieved from http://goo.gl/1AIJ3f doi:10.1007/1-4020-2967-5_6

Chadli, A. (2015). Micro jeux et simulation multi-agents participative: apprentissage des procédures de lutte contre les rongeurs arvicoles. Unpublished doctoral dissertation, Université des Sciences et de la Technologie d'Oran.

Country Fire Authority. (2014). Your guide to survival [Computer software manual]. Retrieved from http:// goo.gl/7UzH7g

Crovato, S., Pinto, A., Giardullo, P., Mascarello, G., Neresini, F., \& Ravarotto, L. (2016). Food safety and young consumers: Testing a serious game as a risk communication tool. Food Control, 62, 134-141. doi:10.1016/j. foodcont.2015.10.009

Deterding, S. (2012). Gamification: Designing for motivation. Interaction, 19(4), 14. doi:10.1145/2212877.2212883

Deterding, S., Dixon, D., Khaled, R., \& Nacke, L. (2011, September). From game design elements to gamefulness: defining gamification. In $15^{\text {th }}$ international academic mindtrek conference: Envisioning future media environments (pp. 9-15). ACM. doi:10.1145/2181037.2181040

DeVito, J. A. (2000). The elements of public speaking (7th ed.). New York, NY: Longman.

Di Loreto, I., Mora, S., \& Divitini, M. (2012, June). Collaborative serious games for crisis management: An overview. In Workshop on enabling technologies: Infrastructure for collaborative enterprises. IEEE. doi:10.1109/ WETICE.2012.25 
Drogoul, A., Amouroux, E., Caillou, P., Gaudou, B., Grignard, A., Marilleau, N., \& Zucker, J. D. (2013). GAMA: A Spatially Explicit, Multilevel, Agent-Based Modeling and Simulation Platform. In Y. Demazeau, T. Ishida, J. M. Corchado, \& J. Bajo (Eds.), Advances on Practical Applications of Agents and Multi-Agent Systems (PAAMS) (pp. 271-274). Salamanca, Spain: Springer. doi:10.1007/978-3-642-38073-0_25

Drogoul, A., Grignard, A., Gaudou, B., Vo, D.-A., Huynh, N.-Q., \& Taillandier, P. (2013). Gama 1.6: Advancing the art of complex agent-based modelling and simulation. PRIMA 2013. Principles and Practice of MAS., 8291, $117-131$.

Dugdale, J., Bellamine-Ben Saoud, N., Pavard, B., \& Pallamin, N. (2010). Simulation and Emergency Management. In B. Van de Walle, M. Turoff and S.R. Hiltz (Eds.), Information Systems for Emergency Management. Sharp.

Dutta, R., Das, A., \& Aryal, J. (2016, February). Big data integration shows Australian bushfire frequency is increasing significantly. Royal Society Open Science, 3(2), 150241. Retrieved from https://goo.gl/kRcZUU doi:10.1098/rsos.150241 PMID:26998312

Guha-Sapir, D., Below, R., \& Hoyois, Ph. E. M.-D. A. T. The CRED/OFDA International Disaster Database. Retrieved from http://www.emdat.be

Haferkamp, N., Kraemer, N. C., Linehan, C., \& Schembri, M. (2011). Training disaster communication by means of serious games in virtual environments. Entertainment Computing, 2(2), 81-88. doi:10.1016/j. entcom.2010.12.009

Hamari, J., Koivisto, J., \& Sarsa, H. (2014). Does gamification work? A literature review of empirical studies on gamification. In HICSS.

Huotari, K., \& Hamari, J. (2012, October 3-5). Defining gamification: a service marketing perspective. In $16^{\text {th }}$ international academic mindtrek conference, Tampere, Finland (pp. 17-22). ACM. doi:10.1145/2393132.2393137

Kinateder, M. T., Kuligowski, E. D., Reneke, P. A., \& Peacock, R. D. (2014). A review of risk perception in building fire evacuation (Tech. Rep. No. 1840). USA: National Institute of Standards and Technology (NIST).

Kleiboer, M. (1997). Simulation methodology for crisis management support. Journal of Contingencies and Crisis Management, 5(4), 198-206. doi:10.1111/1468-5973.00057

Mancheva, L., \& Dugdale, J. (2016). Understanding Communications in Medical Emergency Situations. In HICSS (pp. 198-206). .

Manoj, B. S., \& Baker, A. H. (2007). Communication challenges in emergency response. Communications of the ACM, 50(3), 51-53. doi:10.1145/1226736.1226765

Marczewski, A. (2013a). Gamification user types. Retrieved from http://marczewski.me.uk/user-Types/

Marczewski, A. (2013b). Understanding intrinsic motivation with RAMP.

McGinnis, T., Bustard, D. W., Black, M. M., \& Charles, D. K. (2008). Enhancing E-Learning engagement using design patterns from computer games. In 1st int. conference on Advances in Computer-Human Interaction.

McLennan, J., \& Elliott, G. (2011). Community members decision making under the stress of imminent bushfire threat - Murrindindi fire (Tech. Rep.). Bundoora, Victoria, Australia: Bushfire CRC Extension, School of Psychological Science, La Trobe University.

Michael, D., \& Chen, S. (2006). Serious games: Games that educate, train, and inform. Boston, MA: Thomson Course Technology.

Miller, C., Hilton, J., Sullivan, A., \& Prakash, M. (2015). Spark: A bushfire spread prediction tool. Environmental Software Systems. Infrastructures. Services and Applications, 448, 262-271.

Palttala, P., Boano, C., Lund, R., \& Vos, M. (2012). Communication gaps in disaster management: Perceptions by experts from governmental and non-governmental organizations. Journal of Contingencies and Crisis Management, 20(1), 2-12. doi:10.1111/j.1468-5973.2011.00656.x

Parunak, H., Savit, R., \& Riolo, R. (1998). Agent-based modeling vs equation-based modeling: A case study and users' guide. In Multi-agent systems and agent-based simulation (pp. 10-25). Springer. doi:10.1007/10692956_2 
Petty, R., \& Cacioppo, J. (1986). The elaboration likelihood model of persuasion. Advances in Experimental Social Psychology, 19, 123-205. doi:10.1016/S0065-2601(08)60214-2

Prager, K. (2012). How to apply theories of behaviour change to seweb and related public engagement activities (Tech. Rep.). Invergowrie Dundee, Scotland: James Hutton Institute - Scotland's environment.

Radianti, J., Granmo, O.-C., Sarshar, P., Olsen, M. G., Dugdale, J., \& Gonzalez, J. J. (2015). A spatio-temporal probabilistic model of hazard- and crowd dynamics for evacuation planning in disasters. Applied Intelligence, 42(1), 3-23. doi:10.1007/s10489-014-0583-4

Ran, Y. (2011). Considerations and suggestions on improvement of communication network disaster countermeasures after the Wenchuan earthquake. IEEE Communications Magazine, 49(1), 44-47. doi:10.1109/ MCOM.2011.5681013

Rhodes, A. (2014). Why don't they do what we think they should? understanding people's response to natural hazards.

Roberts, B., \& Lajtha, C. (2002). A new approach to crisis management. Journal of Contingencies and Crisis Management, 10(4), 181-191. doi:10.1111/1468-5973.00195

Sauve, L., Renaud, L., \& Gauvin, M. (2007). Une analyse des écrits sur les impacts du jeu sur l'apprentissage. Revue des Sciences de l'Education, 33(1), 89-107. doi:10.7202/016190ar

Schultz, F., Utz, S., \& Goritz, A. (2011). Is the medium the message? perceptions of and reactions to crisis communication via Twitter, blogs and traditional media. Public Relations Review, 37(1), 20-27. doi:10.1016/j. pubrev.2010.12.001

Searle, J. R. (1969). Speech acts: An essay in the philosophy of language. Cambridge University Press. doi:10.1017/CBO9781139173438

Shahri, A., Hosseini, M., Phalp, K., Taylor, J., \& Ali, R. (2014). Towards a code of ethics for gamification at enterprise. In The practice of enterprise modeling (Vol. 197, pp. 235-245). Manchester, UK: Springer. doi:10.1007/978-3-662-45501-2_17

Shannon, C. E. (1948). A mathematical theory of communication. Bell System Technical Journal, 27, 379-423, 623-656.

Steelman, T. A., \& McCaffrey, S. M. (2013). Best practices in risk and crisis communication: Implications for natural hazards management. Natural Hazards, 65(1), 683-705. doi:10.1007/s11069-012-0386-z

Steelman, T. A., McCaffrey, S. M., Velez, A. L. K., \& Briefel, J. A. (2015). What information do people use, trust, and find useful during a disaster? Evidence from five large wildfires. Natural Hazards, 76(1), 615-634. doi:10.1007/s11069-014-1512-x

Taillandier, F., \& Adam, C. (2017). A serious game for teaching natural risk management. In Social simulation conference $(S S C)$. Dublin: Springer.

Teague, B., McLeod, R., \& Pascoe, S. (2009a). Final report (Tech. Rep.). Melbourne: Victorian Bushfires Royal Commission.

Teague, B., McLeod, R., \& Pascoe, S. (2009b). Final report - volume 4 - the statements of lay witnesses (Tech. Rep.). Victorian Bushfires Royal Commission.

Urban, R., \& Oulehlová, A. (2017). Computer simulation - efficient tool of crisis management. In International Conference Knowledge-Based Organization (pp. 135-141). De Gruyter Open. doi:10.1515/kbo-2017-0167

Utz, S., Schultz, F., \& Glocka, S. (2013). Crisis communication online: How medium, crisis type and emotions affected public reactions in the Fukushima Daiichi nuclear disaster. Public Relations Review, 39(1), 40-46. doi:10.1016/j.pubrev.2012.09.010

Vallerand, R. J. (1993). The academic motivation scale: A measure of intrinsic, extrinsic, and amotivation in education. Educational and Psychological Measurement, 52.

van Ruijven, T. (2011). Serious games as experiments for emergency management research: A review. In 8th international ISCRAM conference, Lisbon, Portugal. 
Vanderveken, D. (1990). Meaning and speech acts. Cambridge University Press.

Werbach, K. (2014). (re) defining gamification: A process approach. In International conference on persuasive technology (pp. 266-272). Springer.

Yudkowsky, E. (2008). Cognitive biases potentially affecting judgment of global risks. In Global catastrophic risks (pp. 91-119). New York: Oxford Univ. Press.

Carole Adam is an associate professor at the University Grenoble-Alps in France, and member of the HAwAI (Human Aware Artificial Intelligence) Research Team, at the Grenoble Informatics Laboratory (LIG), one of the largest computer science research institutes in France. She has been working in modelling human behaviour and emotions for the last 10 years, and applied this research to agent-based modelling and social simulation for crisis management in various types of disasters. She is now specialising in designing computational serious games for raising awareness about communication issues and biases in human behaviour.

Charles Bailly is a second year PhD student at the Grenoble Informatics Laboratory (LIG), and member of the EHCI team. He participated in this research as part of his Master's internship, and is now interested in Human-Computer Interactions in Augmented Reality for surgery.

Julie Dugdale is an associate professor at the University of Grenoble-Alps in France, and leader of the HAwAI (Human Aware Artificial Intelligence Research) Team, at the Grenoble Informatics Laboratory (LIG) - one of the largest computer science research institutes in France. She has been working in the area of modelling and simulating human behaviour in emergency and management situations for the last 20 years, and has published widely in this area. She has been involved in the ISCRAM community since its inception in 2004 and is a former president of the ISCRAM Association. 